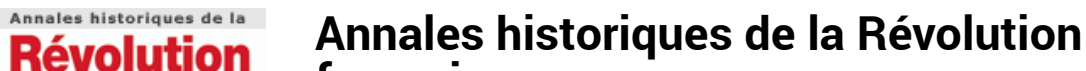 \\ française française
}

326 | octobre- décembre 2001

La Révolution Batave. péripéties d'une République-

Soeur (1795-1813)

\section{Documents sur l'insurrection de Saint-Domingue}

\section{(2) OpenEdition \\ Journals}

Édition électronique

URL : https://journals.openedition.org/ahrf/2683

DOI : $10.4000 /$ ahrf.2683

ISSN : 1952-403X

Éditeur :

Armand Colin, Société des études robespierristes

Édition imprimée

Date de publication : 1 décembre 2001

Pagination : 179-180

ISSN : 0003-4436

Référence électronique

"Documents sur l'insurrection de Saint-Domingue », Annales historiques de la Révolution française [En ligne], 326 | octobre- décembre 2001, mis en ligne le 10 mars 2008, consulté le 24 avril 2022. URL : http://journals.openedition.org/ahrf/2683 ; DOI : https://doi.org/10.4000/ahrf.2683 


\section{DOCUMENTS SUR L'INSURRECTION DE SAINT-DOMINGUE}

\section{Lettre de Sonthonax}

«Au haut du Cap français le 11 février 1793

L'an premier de la république française

\section{Au patriote Milcent}

Je vous adresse, mon cher Milcent, une relation des évènements arrivés au Cap dans les premiers jours de décembre. Vous verrez ce qu'il en coute pour vouloir l'exécution de la loi dans ce malheureux pays. Cependant je suis vainqueur, et croyez bien que la volonté nationale triomphera. Gardez vous de faire envoyer des troupes, nous n'en avons nul besoin. Beaucoup d'argent pour les hopitaux, la station et la solde des tristes restes de l'armée que l'influence mortifère du climat a consommée. Engagez la convention à faire quelque chose pour les esclaves : c'est le seul moyen de la faire chérir. Les misérables se battent pour un roi qu'ils détesteraient si les représentants de la nation osaient se rappeler que les esclaves du nouveau monde se battent pour la même cause que les armées françaises. Adieu.

P.S. :Ne publiez pas ma lettre; elle n'est que pour vous et nos amis. "

Source : AN, AA 55 dossier 1511.

\section{Lettre de Pierrot à Galbaud, transcription.}

$$
\begin{aligned}
& \text { «Au Port français ce } 4 \text { juin } 1793 \\
& \text { Citoyen général }
\end{aligned}
$$

J'ai l'honneur de vous présenter qu'il était venu un de nos frères qui nous a annoncé que vous lui avez chargé de nous communiquer que votre intention est de nous donner la liberté générale et que vous nous demandez pour être défenseur de la colonie à la nation française. Je vous prie, général, de nous donner une assurance par écrit : pour lors, nous pourrions répondre à votre demande. Je vous préviens que l'Espagne et l'Anglais nous ont proposé de nous donner la liberté générale, et même l'on nous fournit de tout. Nous savons que l'on vous fait croire que nous avons reçu des armes de l'Espagne, cela est véritable, mais jusqu'à ce moment nous espérons votre assurance.

Votre très obéissant serviteur

Piérrot général »

\section{Copie de la première phrase de l'original telle quelle :}

"J'ai l'honneur de vous presenté qu'il etoit venu un de nos frère qui nous a anoncer que vous lui avez chargé de nous communiquer que votre intention est de nous donner la liberté général et que vous nous demander pour etre defenseur de la colonie A la nation francais. » 
Latéralement, Galbaud a écrit : «Cette lettre m’a été remise par mon aide de camp de couleur."

Source : AN, AA 54 dossier 1510.

\section{Lettre de Pierrot à Sonthonax, transcription}

\section{«Gouvernement Port français ce 9 juillet 1793}

\section{Citoyen commissaire}

Je vous fais savoir que mes gardes avaient arrêté le courrier du Seman (?) qui apporte des paquets pour vous. Je vous dirai que vos paquets n'ont point été touchés. Si le courrier a été arrêté, c'est comme j'ai appris que vous avez fait sortir une armée pour marcher contre nous qu'il a été arrêté. Mais je vous l'envoie avec toute la sûreté possible, citoyen commissaire. Je suis bien outré contre vos messieurs qui ont arrêté hier plusieurs de mes citoyens qui allaient sur la Tannerie. Vous devez savoir quelles sont mes intentions, vous pouvez vous tranquilliser de mon côté. Je ne me mettrai point en marche contre vous ni contre mes confrères. Soyez sûr que je suis un homme de foi. Je vous demande de me faire les nouvelles du Cap. Nous avons parlé à Jean François quelles étaient nos intentions ainsi que la votre. Il nous a dit qu'il voulait la liberté générale; ainsi, citoyen commissaire, tâchez d'arranger l'affaire le (plus) vite que vous pourrez. Car les nègres ne veulent point marcher contre les Espagnols, même tous ceux du Bas de la Côte sont du même avis comme le notre. Je vous prie de faire lacher mes gens que l'on a pris. Ainsi, commissaire, voyez si j'ai l'intention mauvaise comme l'on vous a rapporté puisque je laisse passer tout le monde. Vous devez voir combien mes sentiments sont grands. Vous savez comme je (me) suis montré quand vous m'avez envoyé chercher pour donner secours en ville. Si l'affaire n'est pas encore arrangé, ce n'est pas de mon côté. Je vous engage d'arranger le plus vite que vous pourrez; car l'on était à la veille de finir avec vous sans votre armée qui sortit hier. Je vous, citoyen, si le Cap est fermé pour moi (sic). J'ai une petite crainte de voir que l'on arrête mes gens au Cap; ainsi je vous prie de donner un ordre (à) tous vos gens de laisser passer mes gens munis d'un passeport de moi. Je suis à espérer votre réponse et croyez moi toujours un de vos fidèles, ne craignez de mon côté, citoyen commissaire. Avec mes sentiments.

Salut Piérrot général »

Enveloppe : Au citoyen

Citoyen Sonthonas

commissaire civil

Nationaux au

Cap

Source : AN, AA 55 dossier 1512. 